\title{
Blocos de solo-cimento para contenção de erosão hídrica
}

\section{Andréa Cristina Thoma1, Eduardo Paranhos Fernandes ${ }^{2}$, Edson Fernandes Rodrigues ${ }^{2}$, Lauana Lopes dos Santos ${ }^{1}$, Alexandre Christofaro Silva ${ }^{1}$ e Bernat Vinolas Prat $^{3}$}

${ }^{1}$ Universidade Federal dos Vales do Jequitinhonha e Mucuri. Faculdade de Ciências Agrárias. Departamento de Agronomia. Programa de Pós-Graduação em Produção Vegetal. Campus JK. Rodovia MGT 367, $\mathrm{km}$ 583, no 5000. Alto da Jacuba. Diamantina-MG, Brasil (CEP 39100-000).

${ }^{2}$ Universidade Federal dos Vales do Jequitinhonha e Mucuri. Laboratório Integrado de Pesquisas Multiusuário dos Vales do Jequitinhonha. Sala LabSaSA. Campus JK. Rodovia MGT 367, km 583, n 5000. Alto da Jacuba. Diamantina-MG, Brasil (CEP 39100-000).

${ }^{3}$ Universidade Federal dos Vales do Jequitinhonha e Mucuri. Faculdade de Ciências Agrárias. Departamento de Agronomia. Programa de Pós-Graduação em Produção Vegetal. Campus JK. Rodovia MGT 367, km 583, no 5000. Alto da Jacuba. Diamantina-MG, Brasil (CEP 39100-000). E-mail: bernatvinolasprat@gmail.com.

Resumo. A erosão antrópica vem se intensificando desde que o ser humano deixou de ser nômade, nos primórdios da agricultura. Vários procedimentos vêm sendo testados e utilizados para minimizar os efeitos da erosão. Nas últimas décadas, artefatos de solo-cimento, facilmente produzidos a baixo custo, têm sido utilizados para controle da erosão. 0 objetivo deste trabalho foi projetar, produzir e testar a resistência de blocos de solo-cimento com formato de meia-lua para aplicação no controle da erosão hídrica. Para a construção destes blocos foi projetada e confeccionada uma fôrma em chapa de aço. Foram realizados quatro traços de cimento $(8 \%, 12 \%, 16 \%$ e $20 \%$ ), que após homogeneização e compactação com solo e água, resultaram em blocos de 8 a $9 \mathrm{~kg}$ e dimensões aproximadas de 3,25 $\mathrm{cm}$ de espessura, $30 \mathrm{~cm}$ de comprimento e $26 \mathrm{~cm}$ de altura. Após o tempo de cura de 7 e 28 dias, os blocos foram submetidos a testes de absorção de água e resistência à compressão. Todos os blocos apresentaram comportamento satisfatório em relação à resistência ao empuxo do solo. Os blocos produzidos com $12 \%$ de cimento foram aqueles com menor custo que resistiram à compressão mínima especificada nas normas técnicas $(\sim 2 \mathrm{Mpa})$ e apresentaram uma absorção de água inferior a 13\%. Os blocos de solo-cimento em formato de meia-lua podem ser utilizados no controle da erosão hídrica.
Recebido

$02 / 05 / 2020$

Aceito

$30 / 08 / 2020$

Publicado

$31 / 08 / 2020$

Acesso aberto

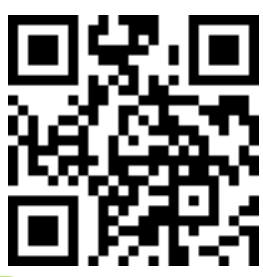

(D) 0000-0002-2753-3160

Andréa Cristina

Thoma

ISSN 2359-1412/RBGAS-2020-00070/2020/7/16/38/1057

Rev. Bras. Gest. Amb. Sustent.

http://revista.ecogestaobrasil.net 
Palavras-chave: Formato de meia-lua; Resistência a compressão; Absorção de água; Talude.

\begin{abstract}
Soil-cement blocks to reduce hidraulic erosion. Anthropic erosion has been intensifying since the human being stopped being nomadic, in the beginning of agriculture. Several procedures have been tested and used to minimize the effects of erosion. In recent decades, soil-cement artifacts, easily produced at low cost, have been used to control erosion. The aim of this work was to design, produce and test the resistance of soilcement blocks with a half-moon shape for application in the control of water erosion. For the construction of these blocks was designed and made a steel sheet form. Four traces of cement were made $(8 \%, 12 \%, 16 \%$ and $20 \%)$, which after homogenization and compaction with soil and water, resulted in blocks of 8 to $9 \mathrm{~kg}$ and dimensions of approximately $3.25 \mathrm{~cm}$ thick, $30 \mathrm{~cm}$ long and $26 \mathrm{~cm}$ high. After the curing time of 7 and 28 days, the blocks were subjected to tests of water absorption and resistance to compression. All the blocks presented satisfactory behavior in relation to the resistance to the thrust of the soil. The blocks produced with $12 \%$ cement were those produced at a lower cost that resisted the minimum compression specified in the technical standards $(\sim 2 \mathrm{Mpa})$ and had water absorption of less than $13 \%$. Soil-cement blocks in the shape of a half-moon can be used to control water erosion.
\end{abstract}

Keywords: Half-moon shape; Compressive strength; Water absorption; Slope.
다 0000-0001-8680-770X

Eduardo Paranhos

Fernandes

(1) 0000-0002-2462-5385

Edson Fernandes

Rodrigues

D) 0000-0002-8788-9951

Lauana Lopes dos

Santos

D) 0000-0003-0418-6175

Alexandre Christofaro

Silva

(D) 0000-0002-0002-2811

Bernat Vinolas Prat

\section{Introdução}

0 processo erosivo do solo é um fenômeno natural que esculpe o relevo e conforma as paisagens do Planeta Terra (Brady e Weil, 2009). A erosão é intensificada quando o homem intervém no ambiente, desmatando, preparando áreas para a agricultura e para obras de infraestrutura. A erosão degrada progressivamente os solos, comprometendo sua fertilidade e sua disponibilidade de água, diminuindo paulatinamente sua capacidade de manter uma cobertura vegetal densa e protetora (Oliveira et al., 2012).

A declividade do terreno e as condições climáticas são responsáveis pelo escoamento, fazendo com que as águas causem um impacto de desagregação do solo em frações mais finas que consequentemente são arrastadas pela corrente. A declividade, a forma e o comprimento da rampa influenciam de forma significativa a velocidade e desenvolvimento do escoamento da água. A intensidade da precipitação pluviométrica e a coesão do solo influenciam sua desagregação e o deslocamento do material para as partes mais baixas da paisagem, a jusante. A força erosiva da água pode variar de acordo com muitos fatores, sendo eles a espessura da lâmina d'água, velocidade do escoamento, dimensão da vertente, presença ou ausência de vegetação e da inclinação (Magalhães, 1995).

Dentre as várias técnicas de manejo de solos voltadas ao controle da erosão, uma das mais utilizadas é a curva de nível, com a função de diminuir a velocidade do defluxo superficial em áreas agrícolas, principalmente nas mais declivosas (Magalhães, 2001). Em 
taludes, técnicas de custo elevado, como os gabiões, as mantas vegetais e o "bidin" são frequentemente utilizados (Passos, 2018). Todas estas técnicas objetivam interceptar a água e diminuir a velocidade do defluxo, minimizando assim, a energia de erosão da água de escoamento.

Outra opção utilizada é a instalação de blocos de concreto ou solo-cimento suficientemente resistentes e colocados na superfície do escoamento da água. A água, ao impactar com estes blocos, perde energia e, consequentemente, diminui sua capacidade de erosionar o solo ou o talude.

O solo-cimento é um material constituído pela homogeneização do solo, cimento e água, compactada e curada (Grande, 2003). É um material cada vez mais utilizado, tanto pelas vantagens técnicas, econômicas, baixo custo e a possibilidade de usar o solo do local onde será empregado (Mieli, 2009). As principais aplicações do solo-cimento são na pavimentação de ruas e estradas, na construção de habitações (tijolos, blocos, lajotas, paredes monolíticas, fundações e pisos) e em obras de contenção, incluindo controle de erosão em taludes (Pariz e Welder, 2005).

Para a contenção de taludes podem ser utilizados blocos de solo-cimento (Sampaio e Nunes, 2015). Muitas das aplicações do solo-cimento para contenção de taludes são feitas mediante o uso do solo-cimento ensacado, permitindo arrimos do tipo de gravidade (Silva et al., 2019). Segundo Ramos (2019), a utilização de solo-cimento ensacado para construção de muros de arrimo é uma ótima opção, pois o mesmo pode ser implantado em diversos locais, tornando viável ser construído pela própria comunidade. Na produção, inicialmente a massa de solo-cimento fresco é colocada em sacarias que, depois de costuradas, são posicionadas no local. Os sacos tem função de servir como fôrma e podem ser de diferentes materiais. Alguns requisitos genéricos devem ser atendidos para poder manter a qualidade do solo-cimento, sendo eles: a quantidade de cimento, de água e a massa específica aparente seca a ser alcançada pós-compactação. 0 traço 1:12 com o Cimento Portland CP-II-E-32 e a resistência mínima de 1,7 Mpa foram definidas como os mínimos aceitáveis (Grande,2003).

Riva (2014) utilizou tijolos de adobe na contenção de taludes como recipiente para o desenvolvimento da vegetação, protegendo assim, a superfície do talude contra o impacto da gota de chuva, reduzindo o escoamento superficial da água e promovendo o aumento da estabilidade do talude após o desenvolvimento do sistema radicular. A primeira etapa consiste na implantação das estruturas na superfície do talude. Por orifício central do talude a vegetação se desenvolve e a estrutura passa a compor parte da paisagem. A cobertura foliar passa a proteger o talude do impacto da gota de chuva e o sistema radicular promove o aumento da resistência do solo ao cisalhamento.

$\mathrm{Na}$ literatura se encontram vários trabalhos sobre o uso de solo-cimento e/ou adobe para contenção da erosão e consequente diminuição da declividade do solo e da velocidade da água. Porem até o momento não foram encontrados trabalhos onde fosse projetado um tijolo de solo-cimento em formato circular para contenção de taludes. Este formato poderia resultar numa maior eficiência no uso do material do solo-cimento, pois permitiria que o material trabalhasse a compressão e diminuiria ao máximo os esforços de tração (Rolim et al., 1999).

O objetivo deste artigo é projetar, produzir e testar a resistência de blocos de solocimento com formato circular (meia-lua) para aplicação no controle da erosão hídrica.

\section{Material e métodos}

\section{Local do estudo}

O trabalho foi conduzido na sala de construções sustentáveis saudáveis localizado no Laboratório Integrado de Pesquisas Multiusuário dos Vales do Jequitinhonha e Mucuri (Lipemvale), da Universidade Federal dos Vales de Jequitinhonha e Mucuri (UFVJM) em 
Diamantina, Minas Gerais. As coordenadas de referência são $18^{\circ} 12^{\prime} 10,0^{\prime \prime}$ S; $43^{\circ} 34^{\prime} 30,7^{\prime \prime} \mathrm{W}$.

\section{Dimensionamento dos equipamentos e da forma}

Foi projetada uma forma para ser preenchida por material de solo-cimento. Depois do preenchimento, foi feita a compactação para posteriormente se proceder a desforma, obtendo um bloco de solo-cimento. Depois do processo de cura (28 dias) o bloco de solocimento poderá adquirir a resistência necessária. Mediante o uso de uma prensa ou equipamento que permita aplicar pressão sobre o solo-cimento e uma forma que permita a colocação do material, é possível criar qualquer formato de bloco. $\mathrm{Na}$ hora de projetar o equipamento para criação de um produto de solo-cimento, um aspecto chave é conhecer a pressão que será aplicada no solo-cimento. Esta pressão que vai permitir dimensionar a fôrma e o elemento que aplica a pressão.

Quando tratado da pressão/força de trabalho sobre a mistura na prensagem, as normas brasileiras (NBR) não trazem nenhuma referência ou valor de pressão/força que devem ser utilizadas sobre a mistura de solo-cimento. Assim, algumas fontes divergem sobre o valor exato para utilização. Segundo Grande (2003) a prensa hidráulica deve aplicar uma pressão sobre a mistura de solo-cimento entre $2 \mathrm{MPa}\left(20,4 \mathrm{kgf} / \mathrm{cm}^{2}\right)$ a $10 \mathrm{MPa}$ $\left(101,9 \mathrm{kgf} / \mathrm{cm}^{2}\right)$. De acordo com a prensa fabricada pela Máquinas Man, deve-se aplicar sobre a mistura de solo-cimento uma força de 8 toneladas (ou seja uma pressão de $31,6 \mathrm{kgf} / \mathrm{cm}^{2}$, considerando uma área de prensagem de $253 \mathrm{~cm}^{2}$ conforme bloco normalizado). Para fabricação de tijolos de solo-cimento em prensa manual, é utilizada uma pressão de aproximadamente 20 a $40 \mathrm{kgf} / \mathrm{cm}^{2}$, e para produção em prensa automatizada, uma pressão de até $100 \mathrm{kgf} / \mathrm{cm}^{2}$ (Pariz e Welder, 2005). Segundo o fabricante RioServ, a mistura de solo-cimento é compactada a uma força de 12 t (ou seja, uma pressão de $47,4 \mathrm{kgf} / \mathrm{cm}^{2}$, considerando uma área de prensagem de $253 \mathrm{~cm}^{2}$ conforme o bloco normalizado). A partir destes dados levantados, Pariz e Welder (2005) estipularam:

Uma pressão máxima de trabalho sobre a mistura a ser prensada em torno de $60 \mathrm{kgf} / \mathrm{cm}^{2}$, por ser um valor médio, que atende todas as especificações anteriormente citadas. Também, deve-se ressaltar, não existe uma obrigação de uma precisão muito grande sobre este dado, já que o mesmo não é normalizado.

Para a produção dos blocos de solo-cimento, o formato de meia lua foi projetado e desenvolvido por meio do Software AutoCad. Este formato permite que, uma vez colocado no local, o bloco resista a elevados esforços a compressão e baixos esforços de tração, tal qual o arco romano. Este formato é ideal considerando que os materiais produzidos com solo-cimento possuem maior resistência a compressão $(>2,0 \mathrm{MPa})$, porém baixa resistência a tração (Rolim et al., 1999). A chapa de $5 \mathrm{~mm}$ de espessura foi escolhida para resistir os esforços gerados pela prensagem do material de solo-cimento que preencheu a fôrma em meia lua (Figuras 1, 2, 3 e 4). Posteriormente foi feita uma estrutura que permitisse a prensagem do material de solo-cimento (Figura 5). 


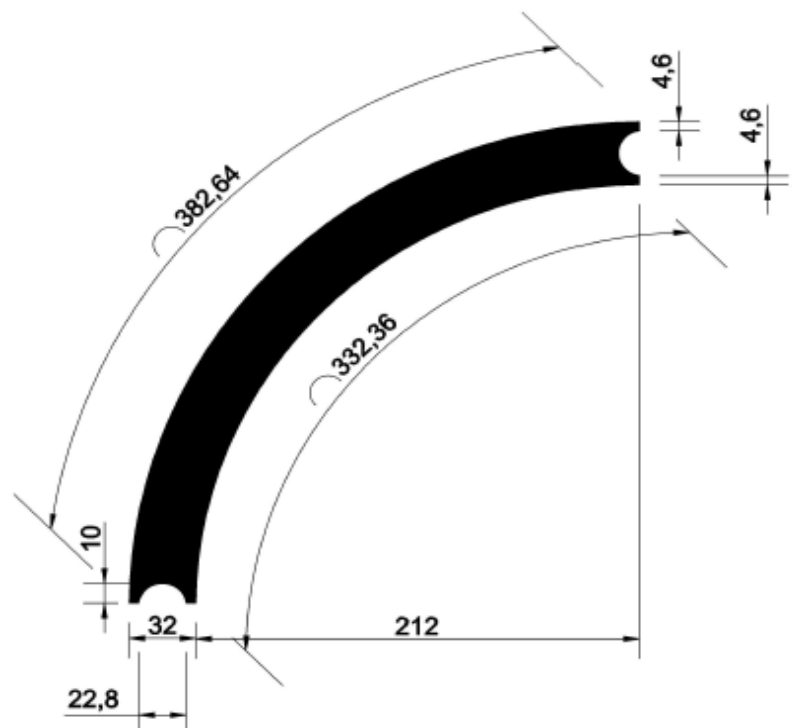

Figura 1. Desenho da Fôrma (Dimensões em mm).

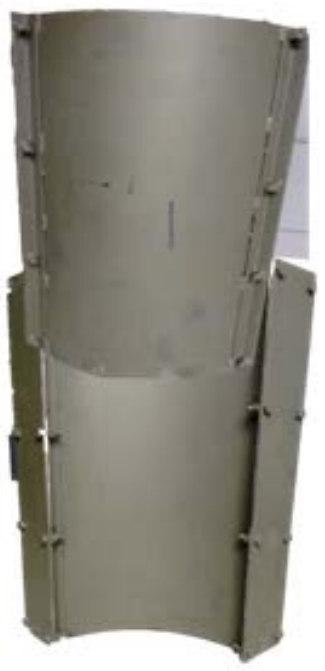

Figura 3. Chapa semicircular.

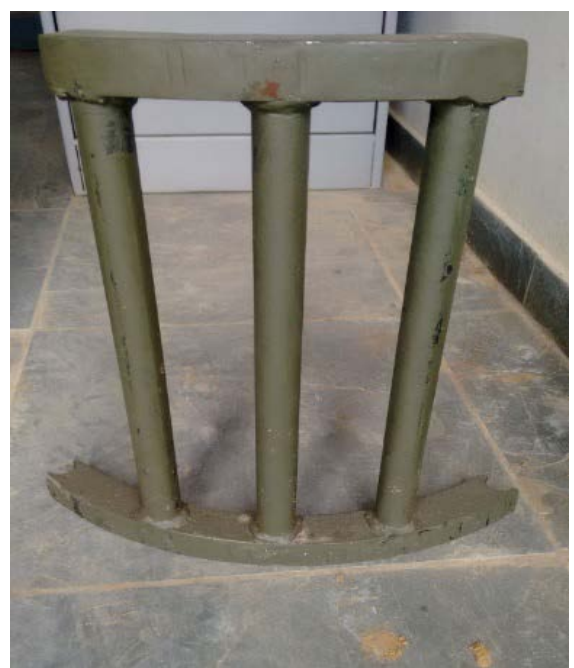

Figura 5. Peça de para prensagem do material na forma.

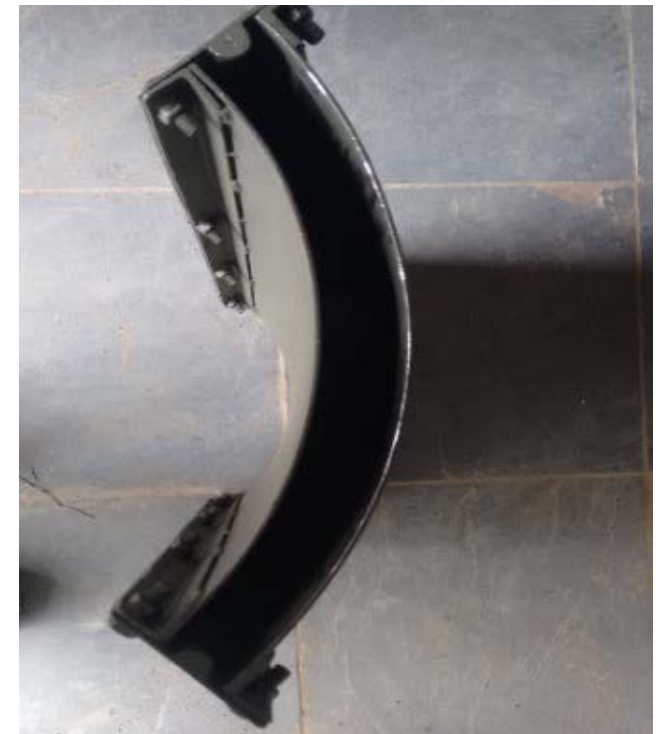

Figura 2. Forma.

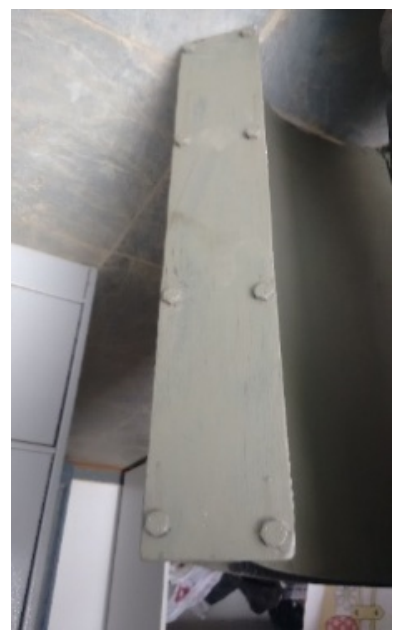

Figura 4. Chapa plana de fechamento.

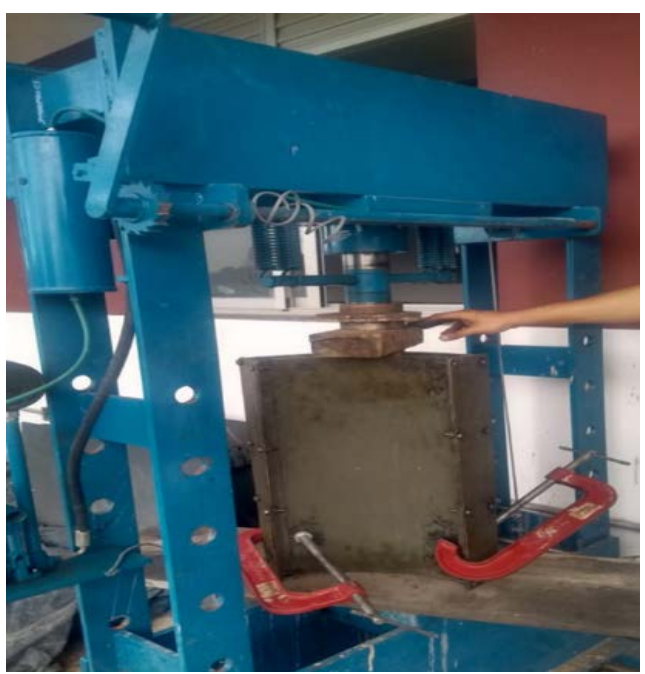

Figura 6. Prensagem do material. 


\section{Produção dos blocos e escolha do traço}

0 solo escolhido como fonte de material foi o Argissolo Amarelo (Embrapa, 2018), solo predominante do campus JK da UFVJM, que apresenta $78 \%$ de areia, $1 \%$ de silte e $21 \%$ de argila.

0 cimento escolhido Portland Pozolânico (CP-IV) que possui baixo calor de hidratação, alto teor de Pozolana (entre 15 e 50\%), o que proporciona estabilidade no uso com agregados reativos e em ambientes de ataque ácido, além de ser altamente eficiente em solo-cimento (Lima et al., 2016).

Foram testados quatro tipos de traço, com $8 \%, 12 \%, 16 \%$ e $20 \%$ de cimento, utilizando-se o delineamento estatístico inteiramente casualizado (DIC), com 4 repetições. Os tratamentos foram os seguintes: em $34,16 \mathrm{~kg}$ de solo utilizou-se 2,73 kg de cimento (8\%), 27,72 kg de solo para 3,32 kg de cimento (12\%), 30,39 kg de solo usou-se 4,86 kg de cimento (16\%) e $31,29 \mathrm{~kg}$ de solo para $6,25 \mathrm{~kg}$ de cimento $(20 \%)$.

Em cada tratamento foram produzidos 4 blocos de 8 a $9 \mathrm{~kg}$ com 12,5\% de umidade. Para homogeneização adicionou-se de 2 a 4,5 litros de água, variando conforme a umidade do dia e exigindo que esta seja isenta de impurezas nocivas à hidratação do cimento, tais como sais, ácidos e matéria orgânica. Para manusear o material utilizou-se enxadas. Imediatamente após a massa estar pronta, foram pesados $9 \mathrm{~kg}$ de massa, enformados e prensados. 0 equipamento utilizado para prensagem foi uma prensa hidráulica manual, com capacidade de 60 toneladas (Figura 6).

Impreterivelmente com a fôrma montada e untada de óleo queimado para facilitar o desprendimento do material prensado, ocorreu a prensagem do material no interior da fôrma com uma pressão de 2,5 toneladas gerando uma tensão aplicada de $22,32 \mathrm{~kg} \mathrm{~cm}^{-2}$ (Equação 1), de modo a comprimir o material, resultando em um bloco de $35 \mathrm{~cm}$ comprimento, 3,2 cm largura e $26 \mathrm{~cm}$ altura (Figura 7).

$$
\text { Tensão aplicada }=\frac{2500 \mathrm{~kg}}{112 \mathrm{~cm}^{2}}=22,32 \mathrm{~kg} \mathrm{~cm}^{-2}
$$

Após a produção, os blocos foram mantidos em armazenamento e hidratação durante o tempo de cura de 26 a 30 dias (Figura 7), posteriormente a este período, foram submetidos a testes de absorção de água e resistência.

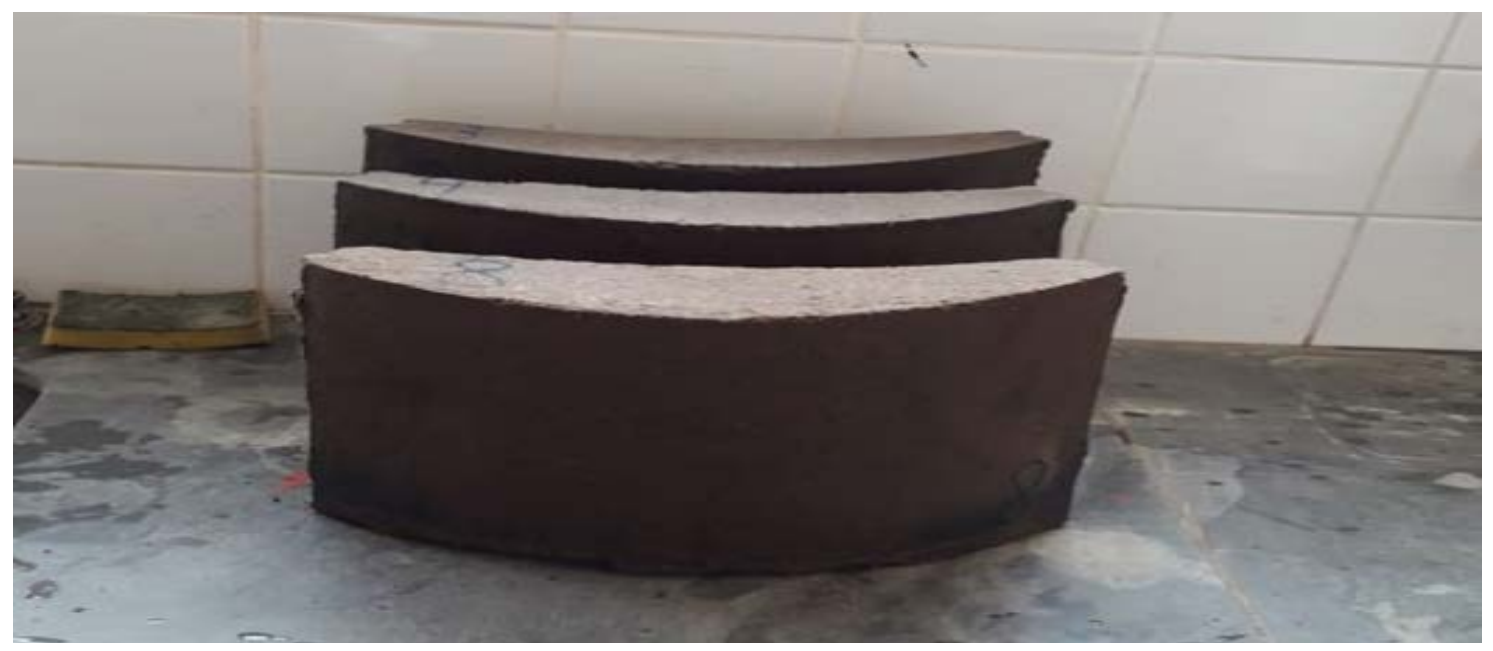

Figura 7. Blocos após cura. 


\section{Análise de absorção de água e resistência}

Após tempo de cura de 28 dias, foram realizados os testes de absorção de água e resistência segundo a normativa ABNT NBR 10836:2013 (ABNT, 2013). Para o teste de absorção, o bloco passou pelo seguinte procedimento: a) secagem em estufa a $105{ }^{\circ} \mathrm{C}$ por $24 \mathrm{~h}$; b) pesagem; c) imersão em água. de água:

Após $24 \mathrm{~h}$, o bloco molhado foi pesado e foi calculada a porcentagem de absorção

$$
\text { \% Absorção }=\frac{X-Y}{Y} \times 100 \quad \text { [equação 2] }
$$

onde: $\mathrm{X}=$ Peso bloco molhado

$\mathrm{Y}=$ Peso bloco seco

Para realizar o teste de resistência do bloco, foi criada uma estrutura metálica onde o bloco foi colocado emborcado, recebendo uma carga pontual em uma barra metálica, colocada de forma longitudinal e centralizada sobre o bloco, a fim de distribuir uniformemente a carga empregada pela prensa no espelho esférico convexo (Figura 8).

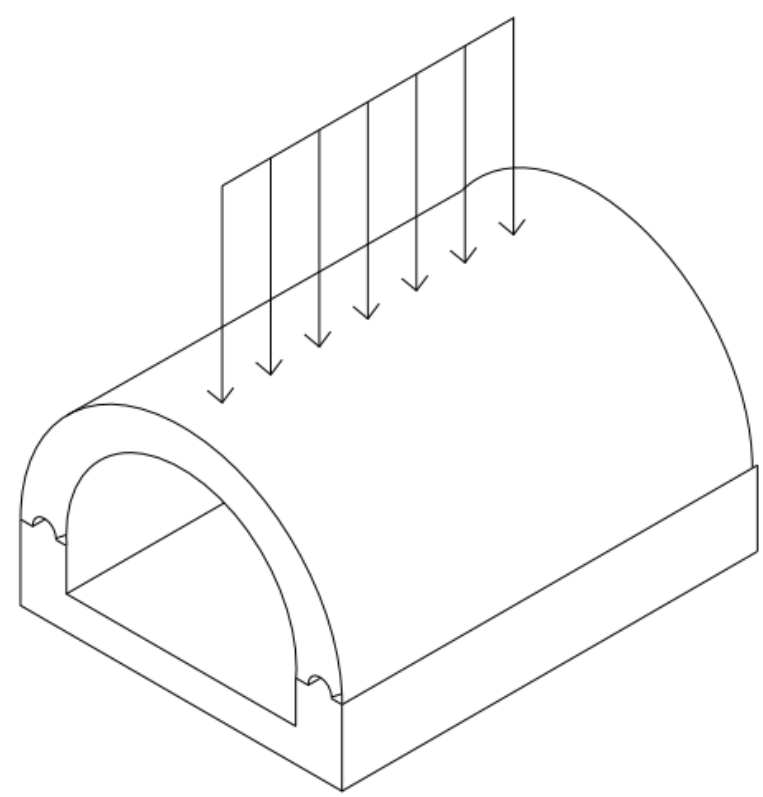

Figura 8. Esquema do teste de resistência.

\section{Análises estatísticas}

Os dados dos testes de resistência e de absorção de água foram analisados por ANOVA e as médias foram comparadas utilizando-se o teste de Tukey $(\mathrm{p}<0,05)$ mediante o aplicativo SPSS Stastistic versão 17.0. As porcentagens de cimento nos traços foram correlacionadas com as resistências mediante o aplicativo Microsoft Excell, de forma a se estimar a porcentagem de cimento para uma resistência de $2 \mathrm{Kpa}$. 


\section{Resultados e discussão}

\section{Absorção de água}

Como observado na Tabela 1 os resultados de absorção de água são bem uniformes, mesmo variando a porcentagem de cimento. Mediante analises ANOVA comparando as medias mediante teste de Tukey se observou que as medias não podem se considerar significativamente diferentes. Como mostrado em outros estudos, à absorção de água não depende da porcentagem de cimento. A absorção de água depende basicamente da umidade de compactação da amostra e da pressão de prensagem. Neste estudo a força de prensagem sempre foi à mesma $\left(22,32 \mathrm{~kg} \mathrm{~cm}^{-2}\right)$ e a umidade de compactação $(12,5 \%)$ também. As variações na umidade são sempre inferiores a $4 \%$ são devidas a não ter uma uniformidade perfeita no processo de produção. Em todos os traços a absorção de água ficou abaixo de $20 \%$, valor máximo que a normativa permite (ABNT NBR 10836:2013) (ABNT, 2013).

Tabela 1. Resultados dos testes de absorção de água.

\begin{tabular}{|c|c|c|c|c|c|c|}
\hline Traço & Tipo & $\begin{array}{c}\text { Peso } \\
\text { seco (kg) }\end{array}$ & $\begin{array}{c}\text { Peso } \\
\text { molhado (kg) }\end{array}$ & $\begin{array}{c}\text { Absorção de } \\
\text { água }\end{array}$ & $\begin{array}{c}\text { Absorção de } \\
\text { água } \\
(\%)\end{array}$ & $\begin{array}{c}\text { Absorção } \\
\text { média } \\
(\%)\end{array}$ \\
\hline \multirow{4}{*}{1 (8\% cimento) } & 1 & 6,70 & 7,52 & 0,82 & 12,3 & \multirow{4}{*}{$12,7 a^{*}$} \\
\hline & 2 & 7,37 & 8,36 & 0,99 & 13,4 & \\
\hline & 3 & 8,92 & 10,22 & 1,31 & 14,7 & \\
\hline & 4 & 7,31 & 8,06 & 0,75 & 10,3 & \\
\hline \multirow{4}{*}{$2(12 \%$ cimento) } & 1 & 6,58 & 7,32 & 0,74 & 11,2 & \multirow{4}{*}{$11,6 a$} \\
\hline & 2 & 6,45 & 7,23 & 0,78 & 12,1 & \\
\hline & 3 & 6,13 & 6,85 & 0,72 & 11,7 & \\
\hline & 4 & 5,67 & 6,32 & 0,65 & 11,5 & \\
\hline \multirow{4}{*}{3 (16\% cimento) } & 1 & 5,84 & 6,58 & 0,74 & 12,6 & \multirow{4}{*}{$13,1 \mathrm{a}$} \\
\hline & 2 & 6,30 & 7,14 & 0,83 & 13,2 & \\
\hline & 3 & 7,25 & 8,26 & 1,01 & 14,0 & \\
\hline & 4 & 7,47 & 8,41 & 0,94 & 12,6 & \\
\hline \multirow{4}{*}{$4(20 \%$ cimento) } & 1 & 7,24 & 8,11 & 0,87 & 12,0 & \multirow{4}{*}{$12,4 a$} \\
\hline & 2 & 6,34 & 7,03 & 0,69 & 10,9 & \\
\hline & 3 & 6,66 & 7,51 & 0,86 & 12,9 & \\
\hline & 4 & 7,59 & 8,64 & 1,05 & 13,9 & \\
\hline
\end{tabular}

*As médias seguidas da mesma letra não diferem entre si pelo teste de Tukey $(\mathrm{p}<0,05)$. Em todas as comparações realizadas mediante software SPSS o grau de significância foi sempre superior a 0.34 .

Trabalhando com blocos de solo-cimento, Grande (2003) obteve absorção média de água de $12 \%$, bem semelhante aos resultados obtidos neste estudo (Tabela 1). A pressão utilizada por Grande (2003) para produção de blocos de solo-cimento $\left(19 \mathrm{~kg} \mathrm{~cm}^{-2}\right)$ foi um pouco menor do que pressão exercida para produção dos blocos em meia lua $\left(22,32 \mathrm{~kg} \mathrm{~cm}^{-2}\right)$.

\section{Resistência do bloco}

O bloco passou por diferentes fases antes da rotura (Figura 8). Quando começa a se produzir o carregamento aparece uma rótula no ponto intermediário do bloco (Figura 9). Posteriormente, as reações que ocorrem nos apoios são as mostradas na (Figura 10), 
devido a uma relação entre a força aplicada no intermédio do bloco (F) com a força de compressão:

$$
\mathrm{F}_{\text {compressão }}=0,15^{*} \mathrm{~F} / 2 / 0,1
$$

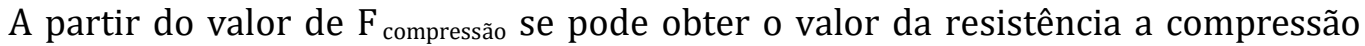

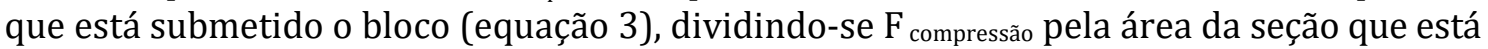
sendo comprimida $(32,5 \mathrm{~mm} \times 250 \mathrm{~mm})$ :

Resistência a compressão do bloco $=\mathrm{F}_{\text {compressão }} /(32,5 \mathrm{~mm}$ x $250 \mathrm{~mm})$ [equação 4]

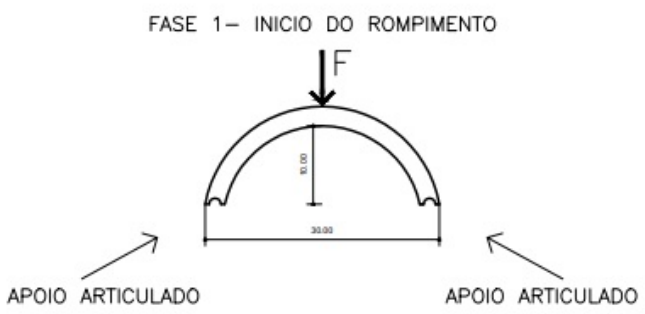

Figura 8. Fase antes da rotura

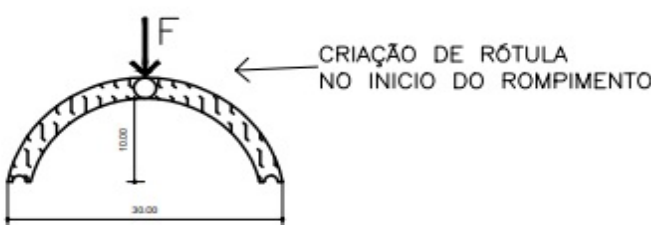

Figura 9.Criação de rótula.

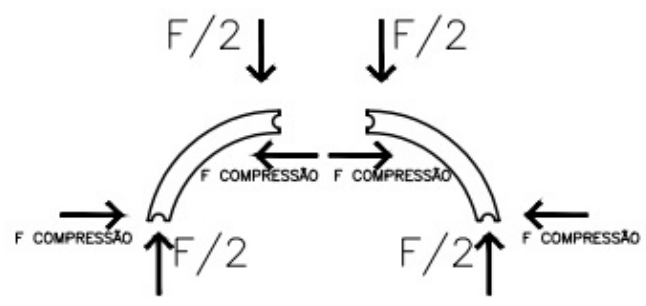

Figura 10. Reações que aparecem nos apoio

$\mathrm{Na}$ Tabela 2 são apresentados os valores de força de rotura do bloco e as resistências à compressão obtidas. Observou-se que à medida que aumenta a quantidade de cimento, a resistência à compressão também aumenta, sendo que quando a porcentagem de cimento em peso fica perto de $15 \%$ o aumento da resistência é menor. Estes valores são um pouco mais baixos quando comparados com valores de compressão de outros estudos. Para blocos de solo-cimento produzidos com $10 \%$ de cimento a média da resistência foi de 2,5 $\mathrm{MPa}$ (Grande, 2003). Neste estudo a resistência média para o bloco feito com $12 \%$ de cimento foi de 1,93 Mpa (Tabela 2). Uma das razões atribuídas à diminuição da resistência pode ser devida ao processo de produção, junto com as fôrmas criadas, que ainda não são eficientes como no caso do bloco de solo-cimento, que possuem maior histórico de pesquisa e vários equipamentos desenhados por empresas especializadas.

Foi realizado um estudo para analisar a correlação entre \% de cimento e resistência atingida à compressão mediante aplicativo Excell. Como modelo teórico para simular a relação entre resistência atingida e \% de cimento foi utilizada uma curva 
logarítmica (Silva e Geyer, 2018). Pois, quanto maior é a quantidade de cimento utilizada, o ganho de resistência para um mesmo incremento de \% de cimento é menor. A curva logarítmica teórica ajustada aos dados obtidos no laboratório foi a que se mostra na equação 4.

$$
\mathrm{Y}=-4,92+2,93 \mathrm{LN}(\mathrm{X})
$$

[equação 4]

onde: $\mathrm{X}=\%$ de cimento.

Y = Resistência a compressão.

Tabela 2. Resultados dos testes de resistência de acordo com o traço.

\begin{tabular}{|c|c|c|c|c|c|c|}
\hline Traço & Tipo & $\begin{array}{c}\text { Força de } \\
\text { rotura } \\
(t)\end{array}$ & $\begin{array}{c}\text { Valor } \\
\text { de F/2 } \\
\text { (t) }\end{array}$ & $\begin{array}{c}\text { Valor de F } \\
\text { compressão (t) }\end{array}$ & $\begin{array}{c}\text { Resistência à } \\
\text { compressão } \\
\text { (MPa) }\end{array}$ & $\begin{array}{c}\text { Média resistência } \\
\text { à compressão } \\
\text { (Mpa) }\end{array}$ \\
\hline \multirow{4}{*}{$\begin{array}{c}1(8 \% \\
\text { cimento) }\end{array}$} & 1 & 1,40 & 0,70 & 1,05 & 1,29 & \multirow{4}{*}{$1,30 a^{*}$} \\
\hline & 2 & 1,42 & 0,71 & 1,07 & 1,31 & \\
\hline & 3 & 1,44 & 0,72 & 1,08 & 1,33 & \\
\hline & 4 & 1,36 & 0,68 & 1,02 & 1,26 & \\
\hline \multirow{4}{*}{$\begin{array}{c}2(12 \% \\
\text { cimento) }\end{array}$} & 1 & 2,10 & 1,05 & 1,58 & 1,94 & \multirow{4}{*}{$1,93 \mathrm{~b}$} \\
\hline & 2 & 2,07 & 1,03 & 1,55 & 1,91 & \\
\hline & 3 & 2,09 & 1,05 & 1,57 & 1,93 & \\
\hline & 4 & 2,08 & 1,04 & 1,56 & 1,92 & \\
\hline \multirow{4}{*}{$\begin{array}{l}3(16 \% \\
\text { cimento) }\end{array}$} & 1 & 3,85 & 1,93 & 2,89 & 3,55 & \multirow{4}{*}{$3,59 \mathrm{c}$} \\
\hline & 2 & 3,87 & 1,93 & 2,90 & 3,57 & \\
\hline & 3 & 3,90 & 1,95 & 2,92 & 3,60 & \\
\hline & 4 & 3,94 & 1,97 & 2,95 & 3,63 & \\
\hline \multirow{4}{*}{$\begin{array}{c}4(20 \% \\
\text { cimento) }\end{array}$} & 1 & 4,03 & 2,01 & 3,02 & 3,72 & \multirow{4}{*}{$3,72 \mathrm{~d}$} \\
\hline & 2 & 3,95 & 1,97 & 2,96 & 3,65 & \\
\hline & 3 & 4,06 & 2,03 & 3,04 & 3,74 & \\
\hline & 4 & 4,11 & 2,05 & 3,08 & 3,79 & \\
\hline
\end{tabular}

*As médias seguidas de diferente letra diferem entre si pelo teste de Tukey $(p<0,05)$. Em todas as comparações realizadas mediante software SPSS o grau de significância foi inferior a 0.02 .

Na Figura 11 se observa a curva do modelo teórico (equação 4), além da curva superior e inferior onde todos os resultados dos rompimentos (indicados com uma cruz no gráfico) ficam dentro de esta faixa. Para poder cumprir com valores normativos obtendo um solo-cimento com resistência maior a $2 \mathrm{MPa}$, se recomenda usar porcentagens de cimento de $12,5 \%$. Os valores obtidos de resistência dependem de muitos fatores além da porcentagem de cimento como: tipo de solo, processo da mistura, clima, dentre outros (Helene e Tutikian, 2005). Recomenda-se então, que quando sejam produzidos estes blocos de contenção em novo local sejam feitos uns primeiros testes de resistência. 0 ideal é começar com dosagens de $12,5 \%$ de cimento e verificar se com esta quantidade de cimento se atinge a resistência a compressão de 2 Mpa. Caso esta resistência seja menor, deverá incrementar-se de forma gradual a porcentagem de cimento. 


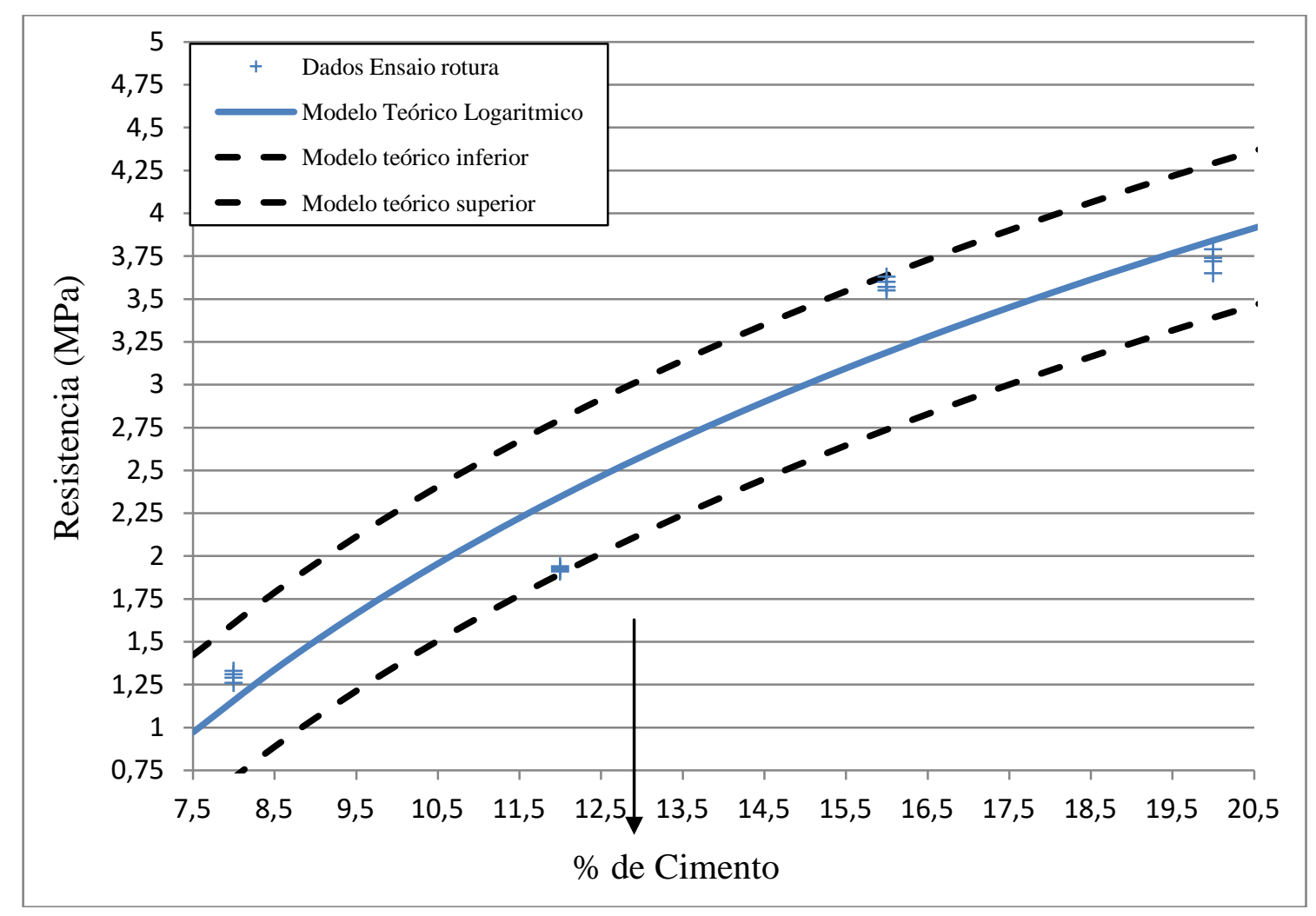

Figura 11. Resistência do bloco de solo-cimento em função da porcentagem de cimento.

Outro aspecto é avaliar a capacidade que deve ter o bloco para suportar as forças de empuxo do solo quando colocado in loco para cumprir a sua missão, a de minimizar a erosão do solo. 0 bloco foi submetido a uma força de empuxo (Figuras 12 e 13).

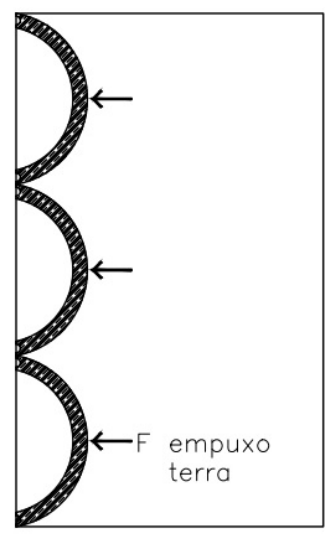

Figura 12. Força de empuxo que o bloco foi submetido.
VISTA LATERAL

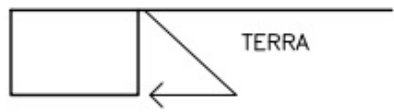

Figura 13. Força que o bloco foi submetido. 
Tendo em conta que o bloco tem uma altura máxima de 0,3 m e uma longitude de 0,3 m a tensão vertical máxima é a seguinte:

$$
\sigma \mathrm{V}=0,3 \mathrm{~m}^{*} 2500 \mathrm{~kg} \mathrm{~m}^{-3}=750 \mathrm{~kg} \mathrm{~m}^{-2} \quad \text { [equação 5] }
$$

Como o solo fica empuxando o bloco e o mesmo pode ser compactado em algum momento, pode-se ter valores da constante k (ver equação 5) de até 3 (Gerscovich et al., 2019). Então a tensão horizontal máxima será de:

$$
\sigma \mathrm{h}=\mathrm{K} \sigma \mathrm{V}=3^{*} 750 \mathrm{~kg} \mathrm{~m}^{-2}=2250 \mathrm{~kg} \mathrm{~m}^{-2} \quad \text { [equação 6] }
$$

Esta tensão faz com que a força horizontal máxima exercida sobre um bloco seja de:

$$
2250 \mathrm{kgm} 2 * 0,25 \mathrm{~m} * 0,3 \mathrm{~m} / 2=84,37 \mathrm{~kg}
$$

Em qualquer caso, estes valores de $84,37 \mathrm{~kg}$ estão muito abaixo da resistência obtida por um bloco deste tipo ( $1.400 \mathrm{~kg}$ no caso do bloco realizado com $8 \%$ de cimento). Então, se pode garantir que este formato de bloco irá resistir ao empuxo do solo.

\section{Conclusões}

- Foi possível projetar e produzir uma forma de bloco de solo-cimento em formato de meia lua, que permite uma eficiência estrutural do mesmo frente aos esforços submetidos na contenção da erosão. 0 bloco de solo-cimento em meia lua sofre basicamente esforços de compressão e os esforços de tração são mínimos.

- A absorção de água dos blocos (independentemente da \% de cimento) foi sempre inferior a 15\%. Este valor cumpre com a normativa ABNT NBR 10836:2013.

- Para obter uma resistência mínima a compressão de 2 Mpa, deve ser colocada uma porcentagem de cimento de $12,5 \%$.

- Este tipo de blocos consegue absorver os esforços do empuxo das terras.

- Este desenvolvimento do novo tipo de bloco de solo-cimento, permite ter uma solução tecnicamente viável com um baixo custo de material e de implementação de equipamentos.

\section{Agradecimentos}

Este estudo foi financiado pela Coordenação de Aperfeiçoamento de Pessoal de Nível Superior (CAPES), Código 001, pelo CNPq (Processo 408162/2018-0) e pela FAPEMIG (Processos PPM 00568-16 e APQ 01000-18).

\section{Conflito de interesses}

Os autores declaram não haver conflito de interesses. 


\section{Referências}

ABNT - Associação Brasileira de Normas Técnicas. ABNT NBR 10836:2013 - Bloco de solo-cimento sem função estrutural - Análise dimensional, determinação a resistência à compressão e da absorção de água - Método de ensaio. Rio de Janeiro: ABNT, 2013.

Brady, N. C.; Weil, R. R. Elementos da natureza e propriedades dos solos. Porto Alegre: Bookman, 2009.

EMBRAPA - Empresa Brasileira de EMBRAPA. Sistema brasileiro de classificação de solos. Rio de Janeiro: EMBRAPA, Centro Nacional de Pesquisa de Solos, 2018.

Gerscovich, D.; Saramago, R.; Danziger, B. R. Contenções: teoria e aplicações em obras. São Paulo: Oficina de Textos, 2019.

Grande, F. M. Fabricação de tijolos modulares de solo-cimento por prensagem manual com e sem adição de sílica ativa. São Paulo: Universidade de São Paulo, 2003. (Tese de doutorado).

Helene, P.; Tutikian, B. Dosagem dos concretos de cimento Portland. In: Isaia, G. C. (Org.). Concreto: ensino, pesquisa e realizações. São Paulo: IBRACON, 2005. v. 2. p. 439-471.

Lima, C. S. B.; Cordeiro, L. C. A.; Ribeiro, R. C.; Jobel Júnior, V.; Guimarães, W. S.; Benarrosh, P. F. P. M. Produção, utilização e vantagens do cimento Portland e CP IV. Revista FAROCIENCIA, v. 4, n. 1, 2016. Disponível em: <https://revistas.faro.edu.br/ FAROCIENCIA/article/view/161>. Acesso em: 23 abr. 2020.

Magalhães, R. A. Processos erosivos e métodos de contenção. Ouro Preto: CEEB, 1995.

Magalhães, R. A. Erosão: definições, tipos e formas de controle. Anais do VII Simpósio Nacional de Controle de Erosão, Goiânia, 2001.

Mieli, P. H. Avaliação do tijolo modular de solo-cimento como material na construção civil. Rio de Janeiro: COPPE/UFRJ, 2009. (Trabalho de conclusão de curso).

Oliveira, F. P. D.; Buarque, D. C.; Viero, A. C.; Merten, G. H., Cassol, E. A.; Minella, J. P. Fatores relacionados à suscetibilidade da erosão em entressulcos sob condições de uso e manejo do solo. Revista Brasileira de Engenharia Agrícola e Ambiental, v. 16, n. 4, p. 337-346, 2012. https://doi.org/10.1590/S1415-43662012000400002

Pariz, S. O.; Welder, A. P. Prensa hidráulica para fabricação de tijolos de solo-cimento. Vitória: Universidade Federal do Espírito Santo, 2005. (Trabalho de conclusão de curso).

Passos, D. D. Alternativas de baixo custo para estabilização de taludes em áreas de risco e estudo de caso na Comunidade do Roger, em João Pessoa-PB. João Pessoa: Universidade Federal da Paraíba, 2018. (Trabalho de conclusão de curso).

Ramos, G. M. P. D.; Freire, G. J. M.; Ferreira, J. R.; Ramos, R. M. C. Contenção de talude com uso de solo-cimento ensacado: Projeto em área de interesse social. RETEC-Revista de Tecnologias, v. 12, n. 2, p. 26-42, 2019.

Riva, N. G.; Diniz, I. S.; Fengler, F. H.; Fredericci, G.; Solera, M. L.; Peche Filho, A.; Medeiros, A.; Ribeiro, A. Simulação da capacidade de carga de tijolos adobe como estruturas de bioengenharia na contenção de taludes. Anais do XI Congresso Nacional de Meio Ambiente, Poços de Caldas, 2014. 
Rolim, M. M.; Freire, W. J.; Beraldo, A. L. Análise comparativa da resistência à compressão simples de corpos de prova, tijolos e painéis de solo-cimento. Revista Brasileira de Engenharia Agrícola e Ambiental, v. 1, p. 93-98, 1999. https://doi.org/10.1590/18071929/agriambi.v3n1p93-98

Sampaio, G. S.; Nunes, I. E. S. Estudo interdisciplinar da viabilidade de aplicação do tijolo de solo-cimento na construção civil: economia aliada à sustentabilidade. Janus, v. 12, n. 22, p. 33-46, 2015.

Silva, A. B. D.; Orlandini, L. S.; Sardinha, I. J. M.; Rankin, D. S. Muros de arrimo: estudo comparativo entre alvenaria estrutural e concreto moldado in loco. Atibaia: Centro Universitário UNIFAAT. 2019. (Trabalho de conclusão de curso).

Silva, D. D. A.; Geyer, A. L. B. Influência da forma do agregado graúdo nas propriedades mecânicas do concreto. Revista Científica Multidisciplinar Núcleo do Conhecimento, v. 5, n. 12, p. 67-82, 2018.

Informação da Licença: Este é um artigo Open Access distribuído sob os termos da Licença Creative Commons Attribution, que permite uso irrestrito, distribuição e reprodução em qualquer meio, desde que a obra original seja devidamente citada. 